\title{
Towards a Framework for Service Ontology Evaluation
}

\author{
Briti Deb \\ DISI, University of Trento, 38050, Povo, Trento, Italy
}

\begin{abstract}
Though there has been a tremendous proliferation in the economic activities involving services, service science as a body of knowledge is still at its infancy. The need for a new service science discipline can be justified by looking at some of the distinguishing characteristics of services such as the coproduction and intangibility. The need is further augmented by governments (for greater GDP growth), businesses (for more profit), academics (for creating novel frontiers of research), and e-commerce (for seamless integration and exchange of information in the semantic web). We believe that a rigorous analysis of ontological foundations of service science would be useful towards the development and understanding of the service concepts and analyzing the validity of relations among them. In this paper we present an ontological evaluation of service related concepts, where we identified situations where ontological inadequacies (such as polysemy) could arise in several service ontologies and SOA standards, using the OntoClean method.
\end{abstract}

\section{General Terms}

Semantic web

\section{Keywords}

Keywords: information integration, OntoClean method, service ontology evaluation, service science

\section{INTRODUCTION}

There has been an tremendous surge in service based economic activities (also known as the tertiary sector), compared to the surge in other economic sectors, namely, secondary sector (manufacturing) and primary sector (agriculture, mining, etc). Methodologies to model typical service characteristics such as intangibility, value co-creation, non-ownership, perishability, variability, etc are yet to be standardized. As more study is needed in both the disciplinary science and information technology to understand the full potential of services [1], analyzing and understanding the basic notions of service becomes essential. This understanding would enable better communication, collaboration, interoperability, and integration between man, machine, and organization, towards realizing seamless information integration in the semantic web. This paper is aimed at facilitating the understanding of concepts related to the Service Science, Service Ontology, and Service oriented architecture Modeling Language (SoaML) through an ontological evaluation, applying the OntoClean [2] method. Hereafter in this paper, service science, service ontology, and Service oriented architecture Modeling Language (SoaML) are together referred to as service ontologies. Service architectures describing business and technology have largely focused on syntactical aspects, ignoring the semantic aspects, resulting to semantic mismatch and difficulty in service communication between man, machine and organization. Lack of common understanding of service concepts between interacting parties creates possibility of polysemy, a phenomenon where the meaning of a term differs in different contexts resulting to confusion, thus hindering growth of semantic web and e-commerce applications. We believe that a framework for ontological evaluation of service ontologies would help to solve such problems encountered by different agents using service.

\section{LITERATURE SURVEY}

The importance of analysis of services at the conceptual level can be dated long back at a paper by Rathmell [3] titled "What is Meant by Services", where he stated that "Certainly any comprehensive approach to the study of service marketing must begin at the conceptual level." Several fundamentals of service science have been described in [4]. More common now-a-days is the emergence of goods-service continuum [3], also known as Product Service System [5], which is evolved by servicization of products (or servicization of goods) and productization of services. A useful comparison with several service systems approaches along with some other developments could be found in [6]. The notion of service has been described by [7] as "... committed to guarantee the execution of some type of action ...", whereas in the information technology (IT) parlance, services are typically referred to as software programs. Furthermore, in the service oriented architectures (SOA) parlance, services are defined as "... repeatable activities that can be characterized as capabilities or the access to capabilities ..." [8]. The increased use of services have resulted to the development of several service and SOA ontologies, which have created a new problem of combining several ontologies [9], thus requiring a framework for evaluating several ontologies.

\section{OUR APPROACH AND ITS BENEFITS}

This paper provides a guide to the problem of service ontology evaluation, such as selection of appropriate methodologies, tools, languages, concepts (terminologies), etc., for analyzing, building, evaluating, or choosing a service ontology. We used the top level (upper) ontology DOLCE [10] for top level ontological distinction of service concepts. To evaluate ontological adequacy of service ontologies, we used the OntoClean [2] methodology. Focus has been given on key service concepts such as Commitment and Role. We believe that this paper will help towards better understanding of service design and engineering, evolution and evaluation of service systems, and help to select suitable parameters for an ontological evaluation of service ontologies.

\section{SYNTACTIC EVALUATION OF SERVICE ONTOLOGIES}

In Table 1, a syntactic evaluation of three significant developments related to service science, SOA ontology, and SoaML, namely [9], [11], and [12] respectively, is presented. It may be clarified here that this paper is not intended as a criticism of any of these viewpoints, rather we aim to provide an ontological evaluation of their design choices. 
Table 1. Syntactic Evaluation of Service Ontologies

\begin{tabular}{|c|c|c|c|}
\hline $\begin{array}{l}\text { Evaluation } \\
\text { Parameters }\end{array}$ & Ref [7] & Ref [11] & Ref [12] \\
\hline $\begin{array}{l}\text { Actual } \\
\text { Applications }\end{array}$ & $\begin{array}{l}\text { Several citations in various } \\
\text { applications such as Cloud } \\
\text { Software Service, Design } \\
\text { Method Supporting the } \\
\text { Alignment between Business } \\
\text { and Software Services, } \\
\text { Ontological Theory of the } \\
\text { Electrocardiogram with } \\
\text { Applications, etc. [Source: } \\
\text { Google Scholar]. }\end{array}$ & $\begin{array}{l}\text { The Open Group (TOG) SOA ontology } \\
\text { [11], along with the Object } \\
\text { Management Group (OMG) SoaML } \\
\text { in [12] can be used as an input to } \\
\text { request for proposals (RFPs) to } \\
\text { extend SoaML with additional } \\
\text { modeling capabilities [8]. }\end{array}$ & $\begin{array}{l}\text { IBM [http://www.ibm.com/us/en/] } \\
\text { supports SoaML in Version 7.5.4 } \\
\text { of Rational Software Architect } \\
\text { and Rational Software Modeler, } \\
\text { with rich set of tools and model } \\
\text { templates to design service } \\
\text { solution. MagicDraw } \\
\text { [https://www.magicdraw.com/] has } \\
\text { planned to bundle SoaML profile. }\end{array}$ \\
\hline Size & $\begin{array}{c}\text { Five main classes along with } \\
\text { several sub-classes found. }\end{array}$ & $\begin{array}{l}\text { Thirteen main classes and other sub- } \\
\text { classes found. }\end{array}$ & $\begin{array}{l}\text { Fifteen main stereotypes and other } \\
\text { sub-stereotypes found. }\end{array}$ \\
\hline \begin{tabular}{|l|} 
Supports \\
Technology \\
(IT) and \\
Business \\
Perspective on \\
SOA
\end{tabular} & $\begin{array}{l}\text { There exists separate concepts of } \\
\text { Commitment (taking care of } \\
\text { business concerns) and Process } \\
\text { (taking care of technology } \\
\text { concerns), separating the issues } \\
\text { of technology and business } \\
\text { perspectives. }\end{array}$ & $\begin{array}{l}\text { The ServiceContract class contains } \\
\text { interactionAspect and legalAspect } \\
\text { datatype property. ServiceContract } \\
\text { class acts as an agreement by defining } \\
\text { how to use a service having terms, } \\
\text { conditions, and interaction rules. The } \\
\text { ServiceInterface class defines the way } \\
\text { in which other elements can interact } \\
\text { with the service. There exist concepts } \\
\text { to support technology and business } \\
\text { aspects of SOA. }\end{array}$ & $\begin{array}{l}\text { The Systems architecture in the } \\
\text { OMG include architecture for } \\
\text { organizations, communities, } \\
\text { processes as well as information } \\
\text { technology systems, enabling } \\
\text { separation of concern such as } \\
\text { "what", "how", "where", "who" } \\
\text { aspects of the service, leveraging } \\
\text { Model Driven Architecture } \\
\text { (MDA) to map business and IT. }\end{array}$ \\
\hline $\begin{array}{l}\text { Support both } \\
\text { Contract } \\
\text { Based and } \\
\text { Interface } \\
\text { Based } \\
\text { Approach to } \\
\text { SOA }\end{array}$ & $\begin{array}{l}\text { Contract based approach provided } \\
\text { by the Commitment and } \\
\text { Interface based approach } \\
\text { provided by the Customized } \\
\text { Service Production concepts. }\end{array}$ & $\begin{array}{l}\text { The ServiceContract class has a } \\
\text { LegalAspect datatype property, } \\
\text { supporting contract based approach. } \\
\text { The ServiceInterface class defines the } \\
\text { way in which other agents interact } \\
\text { with the service, supporting interface } \\
\text { based approach. }\end{array}$ & $\begin{array}{l}\text { In the ServiceContract approach, } \\
\text { interaction between participants } \\
\text { are defined separately from the } \\
\text { participants in a ServiceContract, } \\
\text { which defines the obligations of } \\
\text { all participants, where as in the } \\
\text { ServiceInterface based approach } \\
\text { the interactions between } \\
\text { participants are defined } \\
\text { individually on each participants' } \\
\text { service, and the interface is } \\
\text { requested through prior } \\
\text { agreement between the provider } \\
\text { and the consumer, whose } \\
\text { compatibility determines whether } \\
\text { these agreements are consistent } \\
\text { and connectable or not. }\end{array}$ \\
\hline \begin{tabular}{|l|} 
Representation \\
Aspects of \\
Language \\
(expressivenes \\
s, \\
computational \\
complexity, \\
decidability, \\
reasoning)
\end{tabular} & $\begin{array}{l}\text { Expressed in natural language, } \\
\text { events can be temporally } \\
\text { overlapping, and there exists an } \\
\text { ordering relationship between } \\
\text { events to provide a layered } \\
\text { structure to service. The } \\
\text { ontological dependence requires } \\
\text { that a higher layer event (such as } \\
\text { commitment) must have } \\
\text { occurred for a lower layer event } \\
\text { (such as service production) to } \\
\text { occur. An Unified Modeling } \\
\text { Language (UML) } \\
\text { implementation is proposed in } \\
\text { [13]. }\end{array}$ & $\begin{array}{l}\text { Implemented in Web Ontology } \\
\text { Language-Description Logic (OWL- } \\
\text { DL). UML is also used for exposition } \\
\text { and to illustrate classes and properties, } \\
\text { though the OWL implementation is } \\
\text { more authoritative in terms of having } \\
\text { more rich semantic foundations. }\end{array}$ & $\begin{array}{l}\text { Based on UML2 stereotypes and } \\
\text { profiles, which introduces } \\
\text { extensibility mechanisms for } \\
\text { future growth by adding or } \\
\text { modifying existing functionality. } \\
\text { Stereotypes and profiles also } \\
\text { provide "Semantic Variation } \\
\text { Points", an area where the } \\
\text { semantics are intentionally under } \\
\text { specified to facilitate domain- } \\
\text { specific refinements of the } \\
\text { general UML semantics } \\
\text { [http://www.omg.org/cgi- } \\
\text { bin/doc?formal/05-07-04]. }\end{array}$ \\
\hline $\begin{array}{l}\text { Treatment of } \\
\text { Time }\end{array}$ & $\begin{array}{l}\text { The two spatio-temporal locations } \\
\text { of service production and } \\
\text { service consumption may or } \\
\text { may not coincide, a service may } \\
\text { be delivered in one place and } \\
\text { time and received in another }\end{array}$ & $\begin{array}{l}\text { Treatment of time is not found in detail } \\
\text { explicitly. }\end{array}$ & $\begin{array}{l}\text { The possibility of coincidence of } \\
\text { spatio-temporal locations of } \\
\text { service production and service } \\
\text { consumption is not described } \\
\text { explicitly. Service is provided and } \\
\text { accessed at the Ports, which pre- }\end{array}$ \\
\hline
\end{tabular}




\section{SEMANTIC EVALUATION OF SERVICE ONTOLOGIES}

In Table 2, we applied the OntoClean method to present a semantic evaluation of some of the similar concepts in three significant developments related to service science, SOA ontology, and SoaML, namely [7], [11], and [12] respectively. We again clarify that this paper is not intended as a criticism of any of these viewpoints, rather we aim to provide an ontological evaluation of their design choices.

Table 2. Semantic Evaluation of Service Ontologies

\begin{tabular}{|l|l|l|}
\hline \multicolumn{1}{|c|}{ Ref [7] } & \multicolumn{1}{c|}{ Ref [11] } & \multicolumn{1}{c|}{ Ref [12] } \\
\hline $\begin{array}{l}\text { Commitment - It is an instantaneous, } \\
\begin{array}{l}\text { Service Level Agreement. An agent } \\
\text { who commits is a trustee (provider), } \\
\text { service is a commitment guaranteed by }\end{array}\end{array}$ & $\begin{array}{l}\text { ServiceContract - It is an agreement } \\
\text { binding on all participants, defining the } \\
\text { terms, conditions and interaction rules } \\
\text { that the interacting participants must } \\
\text { consisting to produce content } \\
\text { must be executed. }\end{array}$ & $\begin{array}{l}\text { ServiceContract - A ServiceContract } \\
\text { (providing ServiceDescription and } \\
\text { ServiceInterface) is a binding contract } \\
\text { defining the terms, conditions, interfaces } \\
\text { and choreography. The choreography is } \\
\text { binding on any participant who has a } \\
\text { service port typed by a role in a service } \\
\text { contract, to enable the service, or in other } \\
\text { words, the full specification of a service. }\end{array}$ \\
\hline
\end{tabular}

Ontological discussion of the above row:

In [11], the class ServiceContract, binding on all participants in the interaction, explicitly regulate both the interaction rules and the legal agreements of service use. If we assume that the term "regulate" has been used as a subsumption (isA) relation, then by applying OntoClean methodology, a possible violation of Identity criteria could be found. This is because, though it would be ontologically adequate to make legal aspect subsume ServiceContract class, it would be ontologically inadequate to make interaction aspect also subsume ServiceContract class, due to the violation of OntoClean Identity criteria.

In [12], the distinction between three notions, namely, ServiceContract, ServiceInterface, and ServiceDescription, has been probably blurred. If we assume that ServiceDescription is synonymous to service contract, then a subsumption relation between them seems to be ontologically adequate, but if we assume that ServiceInterface subsume ServiceContract, then there seems to be a violation of Identity criteria, which could possibly be corrected by introducing separate stereotypes such as ServiceDescription, ServiceInterface, and ServiceContract.

In [12], ServiceDescription in provided by ServiceContract and ServiceInterface. The three terms: ServiceDescription, ServiceContract, and ServiceInterface, are three different entities, and our intuition is that if the description is provided by contract and interface, it may lead to confusion in understanding the semantics of those three terms, thus resulting to polysemy.

In the paper by Ferrario-Guarino [7], the Commitment and ServiceDescription are conceived as two different entities, which we believe is ontologically adequate.

Role is discussed in the context of Alters Responsibility Table [7], where services have two orthogonal components: the actions aimed at fulfilling the goals and the modes of participation of stakeholders individuating the role he/she plays in various events in service. Participants plays the role of an agent (the actor in the event) or patient (who undergoes the event and changes state) in an event constituting a service.

\section{"Role class" is not defined because} according to [11], using the Element class with represents property is more general approach to represent the notion of role.
A role defines the basic function (or set of functions) that an entity may perform in a particular context. A ServiceInterface is a UML class and defines specific roles each participant plays in the service interaction. These roles have a name and an interface type. A participant plays a role in the larger scope of a ServicesArchitecture and also plays a role as the provider or user of services specified by ServiceContracts. Each role, or party involved in a ServiceContract is defined by an Interface or ServiceInterface, which is the type of the role. A ServiceContract is a binding contract on any participant that has a service port typed by a role in a service contract. It defines the relationships between a set of roles defined by Interfaces and/or ServiceInterfaces.

Ontological discussion of the above row:

In [11], Element class with represents property is used to conceptualize role, and Actor isA Element, where isA represents subsumption. It also appears in [11] that "Role class is not defined [...]". We believe that such a modeling approach in [11] introduces an ontological problem due to the explicit lack of the notion of role, and due to their particular conceptualization of the 
"role class", which could create confusion on the semantics of the term "role" resulting to polysemy.

In [12], it is assumed that an Entity (which we assume to be as similar to the Element class) plays a role, which we believe, does not introduce any OntoClean Rigidity and Identity constraint violations.

In [7], the concept of role exists, and no ontological inadequacies during modeling of role is visible.

\section{CONCLUSIONS AND FUTURE DIRECTIONS}

We presented an ontological evaluation of service related concepts, and identified potential situations of ontological inadequacies (such as polysemy) in several service ontologies and SOA standards, using the OntoClean method. We believe that this paper would help to harmonize concepts related to Service Science, Service Ontology, and Service-orientedarchitecture Modeling Language, and help to map concepts to top level ontology such as the DOLCE, enabling more dependable semantic web, and seamless information integration for e-commerce. In future, we aim to investigate on the definition and measurement of service quality, service innovation, determination of price of intangible service, better achievement of the SOA goal of business-IT alignment, semiautomatic evaluation of service ontologies, and utilization of ontology towards information integration.

\section{ACKNOWLEDGEMENT}

The author conducted this research during his Master's thesis at the University of Trento.

\section{REFERENCES}

[1] Foster, I.: Service-Oriented Science. Science, 308. 814817. 2005

[2] Guarino, Nicola and Chris Welty. 2002. Evaluating Ontological Decisions with OntoClean. Communications of the ACM. 45(2):61-65. New York:ACM Press.

[3] Rathmell, J. M.: What is Meant by Services, The Journal of Marketing, Vol. 30, No. 4 (Oct., 1966), pp. 32-36.

[4] Maglio, P. P. and Spohrer, J.: Fundamentals of service science. Journal of the Academy of Marketing Science 36(1), 18-20, (2008).

[5] Baines, T. S., et al.: State-of-the-art in product service systems, Proceedings of the Institution of mechanical
Engineers, Part B: Journal of Engineering Manufacture , ISSN 0954-4054 (Print) 2041-2975.

[6] Ferrario R., Guarino N., Trampus R., Laskey K., Hartman A., Gangadharan G. Service System Approaches. Conceptual Modeling Approaches for Services Science. In: The Unified Service Description Language. pp. 75 109. D. Oberle, A. Barros, N. Weissenberg, B. Zarov (eds.). Berlin Heidelberg: Springer Verlag, 2011.

[7] Ferrario R, Guarino N, (2008), Towards and Ontological Foundation for Services Science, In Proceedings of Future Internet Symposium 2008. Springer, Hidelberg.

[8] H. Kreger and J. Estefan, "Navigating the SOA Open Standards Landscape Around Architecture," The Open Group, 2009

[9] M. Klein. Combining and relating ontologies: an analysis of problems and solutions. In IJCAI-2001 Workshop on Ontologies and Information Sharing, pages 53-62, Seattle, WA, 2001.

[10] Masolo, C., A. Gangemi, N. Guarino, A. Oltramari and L. Schneider, (2004), "WonderWeb Deliverable D18: The WonderWeb Library of Foundational Ontologies", available at http://www.loa-cnr.it/Publications.html.

[11] Technical Standard, Service-Oriented Architecture Ontology, as accessed on June 17, 2010, http://www.opengroup.org/projects/soa-ontology/.

[12] OMG, "Service oriented architecture Modeling Language (SoaML), FTF Beta 2", Object Management Group, OMG Document ptc/2009-12-09, December 2009. http://www.omg.org/spec/SoaML/1.0/Beta2/PDF/

13] Ferrario, R., Guarino, N., Janiesch, C., Kiemes, T., Oberle, D., Probst, F.: Towards an Ontological Foundation of Service Science: the General Service Model, 10th International Conference on Wirtschaftsinformatik, Feb. 2011, Zurich, Switzerland 